\title{
PENGARUH GREEN PRODUCT DAN GREEN BRAND AWARENESS TERHADAP GREEN PURCHASE INTENTION
}

\author{
Anggry Tri Hernizar ${ }^{1}$ \\ Asep Muhamad Ramdan ${ }^{2}$ \\ Faizal Mulia ${ }^{3}$
}

\author{
Fakultas Ilmu Administrasi dan Humaniora Universitas Muhammadiyah \\ Sukabumi, Jawa Barat, Indonesia ${ }^{1,2,3}$ \\ Email :Anggryhr@ummi.ac.id ${ }^{1}$, amr37ramdan@ ummi.ac.id ${ }^{2}$, \\ Faizal_88@ummi.ac.id ${ }^{3}$
}

\begin{abstract}
This study aims to study the effect of green products and green brand awareness on green purchase intentions. The variables used in this study are green product (xI) and green brand awareness (x2) as the independent variable and green purchase intention (y) as the dependent variable. This research uses quantitative methods using associative methods. Using questionnaires distributed to 150 respondents. The data analysis technique used is multiple linear regression analysis. The results obtained show a significant significance between green products and green brand awareness of green purchase intentions based on the results of simultaneous and partial hypothesis testing.
\end{abstract}

Keywords: green purchase intention; green brand awareness; green products; green marketing and coffee shop.

\begin{abstract}
ABSTRAK
Penelitian ini bertujuan untuk mengetahui pengaruh green product dan green brand awareness terhadap green purchase intention. Adapun variabel yang digunakan dalam penelitian ini yaitu green product $(\mathrm{x} 1)$ dan green brand awareness $(\mathrm{x} 2)$ sebagai variabel independent dan green purchase intention (y) sebagai variabel dependent. Penelitian ini menggunakan metode kuantitatif dengan pendekatan asosiatif. Menggunakan penyebaran kuesioner yang disebarkan kepada 150 responden. Teknik analisis data yang digunakan yaitu analisis linear regresi berganda. Hasil yang didapatkan menunjukan adanya pengaruh yang signifikan antara green product dan green brand awareness terhadap green purchase intention berdasarkan hasil pengujian hipotesis secara simultan dan parsial.
\end{abstract}

Kata Kunci: green purchase intention; green brand awareness; green product; green marketing dan coffee shop. 


\section{PENDAHULUAN}

Green marketing belakangan ini menjadi gaya baru dalam pemasaran, kemunculan konsep ini terjadi di Eropa awal tahun 1970-1980 ditandai dengan adanya produksi barang yang memberikan dampak berbahaya untuk lingkungan dan diadakan lah seminar mengenai ecological marketing oleh the American Marketing Association dan menghasilkan gagasan green marketing (kaur,2014) Di Indonesia muncul kurang lebih pada tahun 2000an dengan semangat go green (kompasiana, 2010)Green marketing memperkenalkan produk yang ramah lingkungan dan mampu melihat sisi pasar yang berbeda sebagai alternatif perusahaan dalam meningkatkan Green purchase intention (Doszhanov \& Ahmad, 2015).

Green purchase intention merupakan salah satu investasi di masa depan (Doszhanov \& Ahmad, 2015) adanya peningkatan green purchase intention ditandai dengan munculnya product yang ramah lingkungan dan keinginan konsumen dalam melakukan langkah go green serta melakukan referensi terhadap orang lain mengenai green product (Alamsyah, 2018).

Dewasa ini langkah go green terlihat dengan adanya perusahan - perusahan yang memikirkan dampak terhadap lingkungan serta keinginan konsumen yang berkembang yakni dengan menginginkan produk-produk yang ramah lingkungan (Made et al., 2017) Green product merupakan inovasi pemasaran "green marketing" melalui langkah mengurangi sampah limbah plastik salah satunya pengurangan plastik sedotan (Nandini, 2018) dengan menggantinya menggunakan 
bahan yang aman dan dapat digunakan kembali atau reuse karena dianggap lebih ramah pada lingkungan dibandingkan sedotan plastik (Chaerunisa, 2019)

Kesadaran konsumen akan adanya green product dalam meningkatkan kemampuan konsumen untuk mengingat brand ramah lingkungan dan mewujudkan persepsi positif mengenai produk ramah, lingkungan (Doszhanov \& Ahmad, 2015) kesadaran akan lingkungan telah dilakukan di Indonesia dengan adanya kampanye mengenai pengurangan plastik dikalangan para pembinis (Huda, 2019).

Bisnis yang kini sedang berkembang pesat yakni coffee shop, selain menawarkan berbagai kopi kepada para konsumen, kini mereka mulai melakukan go green karena banyaknya isu mengenai dampak bahaya pada lingkungan mengenai limbah plastik, coffee shop identik dengan penggunaan sedotan dan cup yang berbahan plastik, sehingga mereka mulai menciptakan minat beli yang berbasis ramah lingkungan(Pancoro \& Zuliestiana, 2018). Pada dasarnya sebuah bisnis tergantung pada kemampuan perusahaan dalam memasarkan produk ramah lingkungan yang dapat diterima dikalangan masyarakat (Grant, 2007).

Seperti halnya penelitian niat beli yang merupakan green purcahase intention telah diteliti dari tahun ke tahun bahwa adanya pengaruh yang signifikan antara green product dan green brand awareness terhadap green purchase intention (Agustin, Kumadji, \& Yulianto, 2015; Almuarief, 2016; Huang, Yang, \& Wang, 2014; Mahmoud, 2018; Norazad, 2016; Sari \& Widowati, 2014). Sedangkan penelitian (Rahmi, Rozalia, Chan, Anira, \& Prima, 2017) menyatakan tidak adanya pengaruh yang siginifikan. 
Green product merupakan produk yang aman bagi lingkungan maupun mahluk hidup (Agustin et al., 2015) dengan tidak menghasilkan sampah yang berlebih dan dapat mengurangi kerusakan lingkungan (Rizki, Lathifah, \& Widyastuti, 2018) serta memiliki kesan ramah lingkungan dengan menggunakan bahan yang tidak berbahaya (Kumar, 2015).

Adapun dimensi green product yang di gunakan oleh (D’Souza, Taghian, Lamb, \& Peretiatkos, 2006) yakni : 1) label, 2) kemasan, 3) persepsi produk. Lain halnya dengan dimensi yang dikemukakan oleh (Rizki et al., 2018) yaitu 1) konten, 2) manufaktur, 3) kinerja, 4) penggunaan.

Maka penelitian ini menggunakan lima dimensi green product yaitu : 1) persepsi produk (D’Souza et al., 2006), 2) Konten (Rizki et al., 2018), 3) polution prevention product (Johanes, Roza, \& Ilunitedra, 2015), 4) material drien product (Johanes et al., 2015), dan packaging (D’Souza et al., 2006; Johanes et al., 2015).

(Mahmoud, 2018) menyatakan adanya hubungan yang signifikan antara komponen green marketing mix yaitu green product terhadap green purchase intention (Agustin et al., 2015; Almuarief, 2016; Norazad, 2016).

$\mathbf{H}_{1}=$ green product berpengaruh positif dan siginifikan terhadap green purchase intention.

Green brand awareness merupakan kemampuan daya ingat konsumen dalam mengingat merek yang ramah lingkungan (Huda, 2019) dengan berdasarkan pada pengenalan merek sebagai merek hijau yang merupakan hasil asosiasi hijau (Gede et al., 2018) sehingga dirancangnya merek sesuai dengan kebutuhan, serta adanya kecenderungan pada merek yang sudah dikenal memungkinkan rasa aman 
(Putri \& Suasana, 2018) dan kesadaran konsumen serta menyadari produk tersebut tidak dapat digantikan (Herlina Debby \& Ai Lili, 2016)mengenai dampak yang timbul bagi lingkungan (Doszhanov \& Ahmad, 2015).

Adapun dimensi green brand awareness yang dijadikan sebagai alat ukur menurut Dengan menggunakan empat dimensi brand awareness (Rangkuti, 2008) yaitu : 1) top of mind, 2) brand recall , 3) brand recognition, 3) unware of brand. senada dengan dimensi yang digunakan oleh Aaker,2010 dalam (Herlina Debby \& Ai Lili, 2016). (Sari \& Widowati, 2014) menyatakan bahwa terdapat pengaruh hubungan yang siginifikan dan positif antara green brand awareness terhadap green purchase intention (Huang et al., 2014; Kurniawan \& Diryana, 2015)

$\mathbf{H}_{2}=$ green brand awareness berpengaruh positif dan signifikan terhadap green purchase intentiont.

Green purchase intention merupakan niat yang dimiliki konsumen untuk mendukung konsep ramah lingkungan. Kemudian memiki rasa kepedulian terhadap masalah lingkungan melalui pencarian infomarsi serta adanya rasa ketertarikan pada suatu produk yang diinginkan (Haery, 2013; Irpansyah, Ramdan, \& Danial, 2019; Ramayah, Lee, \& Mohamad, 2010).

Beragam dimensi untuk mengukur niat beli yang digunakan oleh (Ferdinand, 2002) yaitu 1) minat transaksional, 2) minat referensial, 3) minat prefensial dan 4) minat eksploratif. Dimensi ini senada dengan dimensi yang digunakan oleh (Priansa, 2017).

Maka dimensi yang digunakan yaitu :1) minat transaksional yaitu kecenderungan konsumen dalam membeli suatu produk (Ferdinand, 2002; Priansa, 
2017), 2) minat referensial yaitu kecenderungan dari konsumen ketika mereferensialkan produk kepada pihak lain(Ferdinand, 2002; Priansa, 2017), 3) minat prefensial yaitu ketika konsumen memiliki prefensi utama terhadap suatu produk dan hanya dapat digantikan apabila produk prefensi utama terjadi sesuatu(Ferdinand, 2002; Priansa, 2017) dan 4) minat eksploratif yaitu konsumen selalu mencari informasi mengenai produk yang di minati.

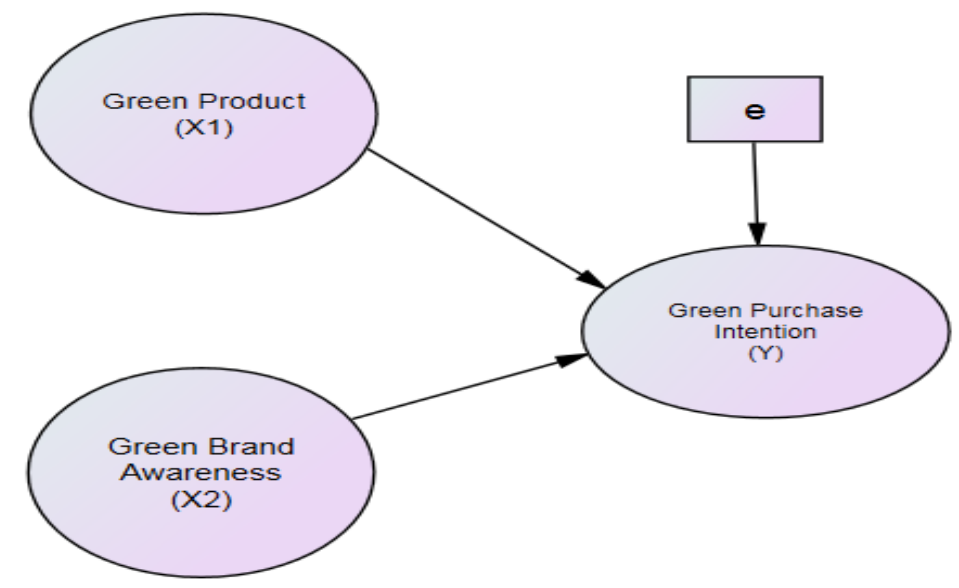

Gambar 1.

Model Penelitian

\section{METODE PENELITIAN}

Penelitian ini dilakukan di coffee shop Sukabumi dengan konsep coffee shop yang melakukan langkah go green. Menggunakan metode penelitian kuantitatif. Dengan teknik pengambilan data menggunakan teknik simple random sampling. Populasi yang digunakan adalah konsumen coffee shop di Sukabumi, penyebaran kuesioner dilakukan kepada 150 responden. Teknik analisis data menggunakan regresi linear berganda dan pengujian model hipotesis yaitu Uji secara parsial dan uji secara simultan. 


\section{HASIL DAN PEMBAHASAN}

Uji Kelayakan Model. Digunakan untuk mengetahui kelayakan model yang digunakan dalam penelitian. Sehingga adapun hasil pengolahan data yaitu:

Tabel 1.

Hasil Uji F

\begin{tabular}{llcccc}
\hline \multicolumn{1}{l}{ Model } & \multicolumn{3}{c}{ ANOVA $^{\mathrm{a}}$} & & \\
& $\begin{array}{c}\text { Sum of } \\
\text { Squares }\end{array}$ & df & $\begin{array}{l}\text { Mean } \\
\text { Square }\end{array}$ & F \\
\hline 1 & Regression & 1089,856 & 2 & 544,928 & 105,897 \\
\hline & Residual & 756,437 & 147 & 5,146 & \\
\hline & Total & 1846,293 & 149 & & \\
\hline
\end{tabular}

Sumber: data diolah

a. Dependent Variable: Green Purchase Intention.

b. Predictors: (Constant), green brand awareness, green product

Menunjukan bahwa nilai $F_{\text {hitung }}$ sebesar 105,897, maka bahwa $F_{\text {hitung }}$ lebih besar dari Ftabel yakni 105,897 > 3,04. serta nilai regresi memiliki tingkatan signifikan ,000 $<0,05$ maka dapat disimpulkan bahwa adanya pengaruh simultan variabel green product dan green brand awareness terdahap green purchase intention sebagai hipotesis dapat diterima.

Tabel 2.

Hasil koefisien determinasi

\begin{tabular}{lllll}
\hline & \multicolumn{4}{c}{ Model Summary } \\
\hline Model & $\mathrm{R}$ & $\mathrm{R}$ & Adjusted & Std. Error of the \\
& & Square & R square & Estimate \\
\hline $\mathbf{1}$ &, 768 &, 590 &, 585 & 2,26844 \\
\hline
\end{tabular}

Sumber: data diolah

a. Predictors : (constanst), green product, green brand awareness

b. Dependen Variable Green purchase intention

Menunjukan bahwa terdapat nilai korelasi sebesar 0,768 dan menunujkan nilai koefision determinasi sebesar 0,585. Dan nilai R Square sebesar ,590 maka 
terdapat pengaruh variabel independent yaitu green product dan green brand awarness terhadap variabel dependen yaitu green purchase intention sebesar $59 \%$ sedangkan sisanya $61 \%$ adanya pengaruh dari variabel lainnya.

Analisis regresi berganda merupakan alat anlaisis untuk mengetahui pengaruh dua variabel bebas terhadap satu variabel terikat (Riduwan, 2014) dengan pengolahan data dengan software IBM SPSS 24.

Uji secara Parsial (Uji T). Dilakukan untuk mengetahui bagaimana hubungan antara variabel satu dengan yang lainya (Lupiyoadi \& Ikhsan, 2015)

Tabel 3.

Hasil regresi linear \& $\mathbf{U j i} \mathrm{T}$

\begin{tabular}{|c|c|c|c|c|}
\hline \multicolumn{5}{|c|}{ Green Product (X1) } \\
\hline & Coeff & SE & $\mathbf{T}$ & P-Value \\
\hline Constant & 0,318 & 1,002 & 0,317 & 0,52 \\
\hline Green Product (X1) & 0,233 & 0,057 & 4,096 & 0,000 \\
\hline \multicolumn{5}{|c|}{ Green Brand Awareness (X2) } \\
\hline & Coeff & SE & $\mathbf{T}$ & P-Value \\
\hline Constant & 0,318 & 1,002 & 0,317 & 0,52 \\
\hline $\begin{array}{l}\text { Green brand } \\
\text { awareness (X2) }\end{array}$ & 0,675 & 0,074 & 9,176 & 0,000 \\
\hline
\end{tabular}

Sumber: data diolah

Menunjukan nilai contasnta (a) sebesar 0,318 dengan nilai green product sebesar 0,232 dan nilai green brand awareness sebesar 0,75, maka hal ini menunjukan adanya kontrtibusi dan pengaruh positif sehingga munculah persamaan regresi dengan rumus (Riduwan, 2014)

$\mathrm{Y}=a+\beta_{1} \mathrm{X}_{1}+\beta_{2} \mathrm{X}_{2}$

maka

$Y=0,138+0,232 X_{1}+0,675 X_{2}$ 
Dinyatakan bahwa variabel green product (X1) memiliki nilai Thitung sebesar 4.096 > 1.976 Ttabel dan dengan nilai signifikan sebesar 0,000 <0,,05 maka adanya pengaruh green product yang positif dan signifikan terhadap green purchase intention, senada dengan penelitian yang dilakukan (Mahmoud, 2018).

Kemudian variabel green brand awareness (X2) memiliki nilai Thitung > Ttabel yaitu 9,176 $>1.976$ dan nilai signifikan $0,000<0,05$ maka adanya pengaruh yang positif dan signifikan antara green brand awareness terhadap green purchase intention, senada dengan hasil penelitian (Sari \& Widowati, 2014).

\section{SIMPULAN DAN SARAN}

Berdasarkan penelitian diatas, maka ditemukan beberapa kesimpulan yang digunakan untuk menjawab pertanyaan penelitian. Dengan menggunakan teknik analisis regresi linear berganda menunjukan bahwa adanya pengaruh variabel independent yang terdiri dari dua variabel yaitu green product (X1) dan green brand awareness (X2) terhadap variabel dependent yaitu green purchase intention (Y) Dan hasil uji hipotesis secara parsial dan simultan menyatakan adanya hubungan positif yang siginifikan secara parsial XI dan X2 terhadap Y.

Adapun beberapa saran yang ditujukan untuk coffee shop sebagai pertimbangan dalam menerapkan green marketing. Yang pertama, green product dapat menjadi acuan coffee shop dalam mendapatkan pangsa pasar, dengan memaksimalkan isu isu mengenai langkah go green sebagai daya tarik dalam mendapatkan minat konsumen mengenai pembelian yang bersifat ramah lingkungan.Kedua, coffee shop yang memulai go green dapat memberikan arahan 
serta ciri khas yang menunjukan eksistensi antar coffee shop yang berkaitan dengan produk-produk ramah lingkungan dengan menggunakan brand yang mereka miliki.

\section{REFERENSI}

Agustin, R. D., Kumadji, S., \& Yulianto, E. (2015). Pengaruh Green Marketing Terhadap Minat Beli Serta Dampaknya Pada Keputusan Pembelian (Survei Pada Konsumen Non-Member Tupperware Di Kota Malang). Jurnal Administrasi Bisnis, 22(2), 37-36.

Alamsyah, D. P. (2018). Meningkatkan Minat Beli Konsumen Pada Produk Ramah Lingkungan Melalui Dukungan Lokasi Konsumen. 18(1), 17-24.

Almuarief. (2016). PENGARUH GREEN MARKETING TERHADAP MINAT BELI YANG DIMEDIASI OLEH BRAND IMAGE (Studi pada Air Minum Dalam Kemasan Ades). UNIVERSITAS NEGERI YOGYAKARTA.

Chaerunisa, F. (2019). Sudah tepatkah nostrawmovement bersama stainless straw. Retrieved January 31, 2020, from Kompasiana website: https://www.kompasiana.com/fchaerunisaa/sc7b5cd1677ffb75894931fd/suda h-tepatkah-nostrawmovement-bersama-stainless-staw

D’Souza, C., Taghian, M., Lamb, P., \& Peretiatkos, R. (2006). Green products and corporate strategy: an empirical investigation. Society and Business Review, 1(2), 144-157. https://doi.org/10.1108/17465680610669825

Doszhanov, A., \& Ahmad, Z. A. (2015). Customers' Intention to Use Green Products: the Impact of Green Brand Dimensions and Green Perceived Value. SHS Web of Conferences, 18(2012), 01008. https://doi.org/10.1051/shsconf/20151801008

Ferdinand, A. (2002). Pengembangan minat beli merek eksistensi. semarang: badan penerbit universitas diponegoro.

Gede, I. N., Bagus, P., Octavia, D., Prodi, S., Bisnis, M., \& Ekonomi, F. (2018). Analisis Persepsi Green Brand terhadap Green Brand Preference pada Starbucks Indonesia Analysis of Green Brand Perception toward Green Brand Preference on Starbucks Indonesia. 5(2), 1682-1690.

Grant, J. (2007). The Green Marketing Manifesto.

Haery, F. A. (2013). Effect of Green Marketing on Consumer Purchase Intentions With Regard to the Company's Image as a Mediator in the Retail Setting Case study: The Customers of Naghshe-e Jahan Sugar Company. 3(11), 442452. https://doi.org/10.6007/IJARBSS/v3-i11/356

Herlina Debby, S., \& Ai Lili, Y. (2016). Pengaruh Tingkat Brand Awareness Terhadap Keputusan Pembelian Produk Victoria' s Secret ( Studi Pada 
Konsumen Victori a' $\mathrm{s}$ Se cret di PVJ Bandung ). EProceedings of Management, 3(1), 497-505.

Huang, Y. C., Yang, M., \& Wang, Y. C. (2014). Effects of green brand on green purchase intention. Marketing Intelligence and Planning, 32(3), 250-268. https://doi.org/10.1108/MIP-10-2012-0105

Huda, F. (2019). Pengaruh Kesadaran Produk Ramah Lingkungan, Citra Merek Hijau dan Kesadaran Harga Terhadap Keputusan Pembelian Tisu Tessa. Intitut Agama Islam Negeri Surakarta.

Irpansyah, M. A., Ramdan, A. M., \& Danial, R. D. M. (2019). Dampak Dari Kekuatan Dan Popularitas Selebgram Terhadap Minat Beli Pada Produk Mode Lokal Di Instagram. E-Jurnal Ekonomi Dan Bisnis Universitas Udayana, 3, 221. https://doi.org/10.24843/eeb.2019.v08.i03.p01

Johanes, Roza, S., \& Ilunitedra. (2015). Pengaruh Green Product Terhadap Brand Image Produk Air Minum Dalam Kemasan Merek Aqua. 1(1), 41-48.

kompasiana. (2010). Pro Green Melalui Green Marketing. Retrieved from https://www.kompasiana.com/hasrulhoesein/55000750a33311ef6f50fa8d/pro -green-melalui-green-marketing

Kumar, P. (2015). Green marketing innovations in small Indian firms. World Journal of Entrepreneurship, Management and Sustainable Development, 11(3), 176-190. https://doi.org/10.1108/wjemsd-01-2015-0003

Kurniawan, G. I., \& Diryana, I. (2015). Impact on Green Purchase Intention by Brand Equity Dimension.

Lupiyoadi, R., \& Ikhsan, R. bramulya. (2015). Praktikum Metode Riset Bisnis. Salemba Empat.

Made, L., Rahayu, P., Abdillah, Y., Mawardi, M. K., Administrasi, F. I., \& Brawijaya, U. (2017). Pengaruh Green Marketing Terhadap Keputusan Pembelian Konsumen ( Survei Pada Konsumen The Body Shop di Indonesia dan di Malaysia ). 43(1), 121-131.

Mahmoud, T. O. (2018). Impact of green marketing mix on purchase intention. International Journal of ADVANCED AND APPLIED SCIENCES, 5(2), 127135. https://doi.org/10.21833/ijaas.2018.02.020

Nandini, W. (2018). sedotan plastik mengancam bumi. Retrieved from Katadata website: https://amp.katadata.co.id/grafik/2018/06/22/sedotan-plastikmengancam-bumi

Norazad, M. S. (2016). Green product purchase intention: impact of green brands, attitude, and knowledge.

Pancoro, I. A., \& Zuliestiana, D. (2018). Pengaruh Green Marketing Terhadap Minat Beli pada Gerai Starbuck di Kota Bandung. 5(2), 1886-1893. 
Priansa, donni juni. (2017). Perilaku konsumen dalam persaingan bisnis kontemporer. Bandung: Penerbit Alfabeta.

Putri, V. D. A., \& Suasana, I. G. A. K. G. (2018). Pengaruh Elemen Ekuitas Merek Terhadap Keputusan Pembelian di Gerai Starbuck Coffee (Studi Pada Konsumen Domestik Starbucks Coffee di Wilayah Bali). 7(1), 470-496.

Rahmi, D. Y., Rozalia, Y., Chan, D. N., Anira, Q., \& Prima, R. (2017). Green brand image, green awareness, green advertisement, and ecological knowledge in improving green purchase intention and green purchase behavior on creative industry products. 20(2), 177-186. https://doi.org/10.14414/jebav.v20i2.1126

Ramayah, T., Lee, J. W. C., \& Mohamad, O. (2010). Green product purchase intention: Some insights from a developing country. Resources, Conservation and Recycling, 54(12), 1419-1427. https://doi.org/10.1016/j.resconrec.2010.06.007

Rangkuti, F. (2008). The Power Of brands: Teknik Mengelola Brand Equity dan Strategi Pengembangan Merek. Jakarta: PT Gramedia Pustaka Utama.

Riduwan. (2014). Pengantar Statistika Sosial. Bandung: Alfabeta.

Rizki, A., Lathifah, A., \& Widyastuti, D. A. (2018). Pengaruh Green Product Terhadap Minat Pembelian Ulang ( Studi pada Produk Lampu LED Merek PHILIPS ). 1(01), 16-28.

Sari, N. P., \& Widowati, R. (2014). Hubungan Antara Kesadaran Merek, Kualitas Persepsian, Kepercayaan Merek dan Minat Beli Produk Hijau. Jurnal Manajemen \& Bisnis, 5(1), 59-79. 